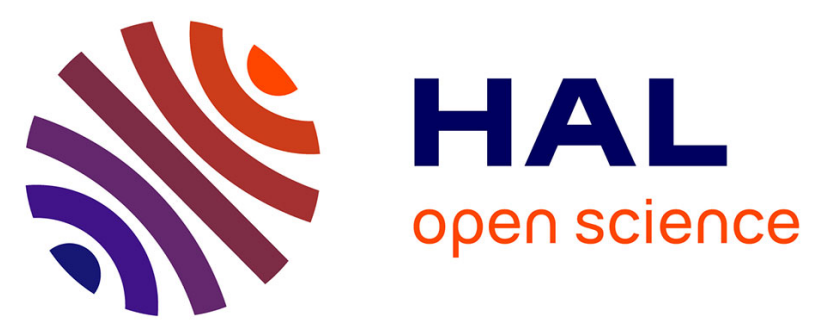

\title{
Uncertainties in assessing annual nitrate loads and concentration indicators: Part 2. Deriving sampling frequency charts in Brittany, France
}

François Birgand, Claire Faucheux, Gérard Gruau, Florentina Moatar, Michel Meybeck

\section{To cite this version:}

François Birgand, Claire Faucheux, Gérard Gruau, Florentina Moatar, Michel Meybeck. Uncertainties in assessing annual nitrate loads and concentration indicators: Part 2. Deriving sampling frequency charts in Brittany, France. Transactions of the ASABE, 2011, 54 (1), pp.93-104. 10.13031/2013.36263 . insu-00609836

\section{HAL Id: insu-00609836 \\ https://hal-insu.archives-ouvertes.fr/insu-00609836}

Submitted on 2 Jun 2020

HAL is a multi-disciplinary open access archive for the deposit and dissemination of scientific research documents, whether they are published or not. The documents may come from teaching and research institutions in France or abroad, or from public or private research centers.
L'archive ouverte pluridisciplinaire HAL, est destinée au dépôt et à la diffusion de documents scientifiques de niveau recherche, publiés ou non, émanant des établissements d'enseignement et de recherche français ou étrangers, des laboratoires publics ou privés. 


\title{
UnCertainties in Assessing Annual Nitrate LOADS AND CONCENTRATION INDICATORS: Part 2. Deriving SAMPling Frequency Charts in Brittany, France
}

\author{
F. Birgand, C. Faucheux, G. Gruau, F. Moatar, M. Meybeck
}

\begin{abstract}
In water quality monitoring programs, standard sampling frequency schemes tend to be applied throughout entire regions or states. Ideally, the common standard among monitoring stations ought not to be the sampling frequency but instead the level of uncertainty of the estimated water quality indicators. Until now, there was no obvious way of doing this. This article proposes, for the first time, guidelines to select appropriate sampling frequencies to harmonize the level of uncertainty in the case of yearly nitrate indicators for the regional river water quality monitoring network in Brittany, France. A database of 50 watershed-year datasets (nine watersheds of 4 to $252 \mathrm{~km}^{2}$ in size) was used for which high temporal resolution data (hourly and daily) were available for flow and nitrate concentrations. For each dataset, the uncertainty levels were calculated by numerically simulating sampling intervals varying from 2 to 60 days. The precision limits of the uncertainties were successfully correlated to a hydrological reactivity index. The correlations were used to derive sampling frequency charts. These charts can be used by watershed managers to optimize the sampling frequency scheme for any watershed for a desired uncertainty level, provided that the dimensionless local hydrological reactivity can be calculated from previous records of continuous flow rates. The sampling frequency charts also suggest that, depending on the hydrological reactivity, expected uncertainties generated by monthly sampling range between $\pm 6 \%$ and $\pm 14 \%$ for the annual load and between $-5 \%$ and $+2.5 \%$ to $+7.2 \%$ for the annual concentration average.
\end{abstract}

Keywords. Concentration indicators, Measurement uncertainty, Nitrate, Nutrient fluxes, Sampling frequency charts, Water quality, Watershed.

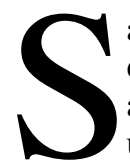
ampling frequencies in regional and national water quality networks are often set to be time proportional (e.g., from bimonthly to bimestrial) and generally uniform across all monitoring stations (e.g., monthly sampling in the implementation of the Water Framework Directive in Europe; EU, 2000). The advantages of using uniform frequencies include, among others, a set schedule for field service and ease of budget allocation. However, it seems quite intuitive that the variability in size and hydrological regime among watersheds of the same network would call for an adjustment of the sampling frequency on a per watershed basis. Indeed, uncertainties of water quality indicators

Submitted for review in February 2010 as manuscript number SW 8437; approved for publication by the Soil \& Water Division of ASABE in December 2010.

The authors are François Birgand, ASABE Member Engineer, Assistant Professor, Department of Biological and Agricultural Engineering; North Carolina State University, Raleigh, North Carolina; Claire Faucheux, Research Consultant, Geovariances, Avon, France; Gérard Gruau, Professor, CNRS-CAREN, Rennes, France; Florentina Moatar, Associate Professor, Laboratoire de Géologie des Environnements Aquatiques Continentaux, Université de Tours, France; and Michel Meybeck, Professor, Laboratoire de Géologie Appliquée, Université Paris, France. Corresponding author: François Birgand, Department of Biological and Agricultural Engineering; North Carolina State University, Raleigh, NC 27695-7625; phone: 919-513-2499; fax: 919-515-7760; e-mail: francois_birgand@ncsu.edu. (e.g., loads, average, median concentrations, etc.) induced by infrequent sampling have been shown to vary considerably between watersheds of variable sizes and hydrological years (e.g., Wang et al., 2003; Moatar et al., 2006; Moatar and Meybeck, 2005, 2007; Johnes, 2007, Moatar et al., 2009; Birgand et al., 2010). The consequences are potential ill comparisons, between watersheds and between years, of water quality indicator values for which the uncertainties may differ by several fold (e.g., Birgand et al., 2010).

Harmonizing uncertainties to a standard level for indicators is key to improving the quality of reported values and to deriving meaningful conclusions about the state and trends in water quality in regional and national monitoring networks. This essentially implies adjusting sampling frequencies on a station by station basis. Until now, however, to our knowledge there has been no detailed report linking the uncertainty level, the sampling frequency, and the watershed characteristics, and proposing sampling frequency recommendations on a case by case basis. Moatar and Meybeck (2007) and Moatar et al. (2009) have shown that the hydrological regime of watersheds could be used to predict uncertainty levels for pollutants usually linked to particles. This work proposes to expand on this approach and derive sampling frequency guidelines as a function of the hydrological reactivity and a desired uncertainty level to annual nitrate fluxes and concentration indicators in Brittany, France. 


\section{METHOD}

The method involved calculating uncertainties induced by infrequent sampling for a dataset of reference watersheds, calculating a hydrological reactivity index for each watershed-year, and correlating the uncertainty values with the reactivity index values. These correlations were then used to extrapolate the uncertainty levels to all reactivity index values. Assuming that the reference watersheds were representative of the general relationship of nitrate concentration and flow rate in Brittany, the correlations were used to derive sampling frequency charts from which sampling guidelines were drawn.

\section{REFERENCE WATERSHEDS}

The equivalent of 50 watershed-year datasets for nine watersheds ( 5 to $252 \mathrm{~km}^{2}$ ) throughout Brittany, France, were used in this study. High temporal resolution nitrate data (hourly or equivalent in most watersheds) were available in addition to continuous flow records (see table 1 in Birgand et al., 2010). Two of the nine watersheds (named Pigeon Blanc and Ville au Chef) had substantial subsurface drainage, which was found to dramatically affect the results (see next section). In this intensive animal-rearing region, the nitrate concentrations and the annual loads were quite high, ranging from 5 to $20 \mathrm{mg} \mathrm{NO}_{3}^{-}-\mathrm{N} \mathrm{L}^{-1}$ and from 15 to $60 \mathrm{~kg} \mathrm{~N}^{-1}$ year $^{-1}$, respectively (details in Birgand et al., 2010). Data were grouped by "hydrologic" years that start at the end of the dry season, usually at the end of summer in France (1 Sept. to 31 Aug.), to incorporate a full hydrological cycle.

\section{CALCULATING UnCERTAINTIES INDUCED BY INFREQUENT SAMPLING}

Calculating the uncertainty involved a three-step process. Reference fluxes and concentration indicators were first calculated from the datasets using all available data. Second, the reference datasets were numerically sampled to simulate discrete sampling at frequencies that ranged from daily to bimestrial. Third, flux (load) estimates and water concentration indicators were calculated and compared to the reference values to estimate uncertainties for a given sampling frequency. Annual nitrate loads were estimated using the flow-weighted average concentration ratio method (referred to as M5), as it was found to perform best for nitrate in Brittany (Birgand et al., 2010). Annual concentration indicators tested include the arithmetic average $\left(C_{\mathrm{avg}}\right)$, the median $\left(C_{50}\right)$, the 90th $\left(C_{90}\right)$ and 95th $\left(C_{95}\right)$ percentiles, and the maximum $\left(C_{\max }\right)$.

It is important to realize that for a given sampling frequency, there are an infinite number of possible sampling dates and times, and hence an infinite number of estimated values and an infinite number of "errors" compared to the reference values. Uncertainties induced by infrequent sampling (expressed as percentage difference compared to the reference values) can thus be characterized by the bias and precision of the distribution of errors. The precision was computed as the interval in which $90 \%$ of the estimated values were included (between the 5th and the 95th percentiles, named herein the precision limits $e_{5}$ and $\left.e_{95}\right)$. The bias was represented by the average value $\left(\mathrm{e}_{\mathrm{avg}}\right)$ of the distribution, although the median $\left(\mathrm{e}_{50}\right)$ value could also be used (fig. 1). Uncertainties were thus characterized for each watershed-year and each sampling interval by the precision limits $\mathrm{e}_{5}$ and $\mathrm{e}_{95}$ and by the bias value $\mathrm{e}_{\text {avg. }}$

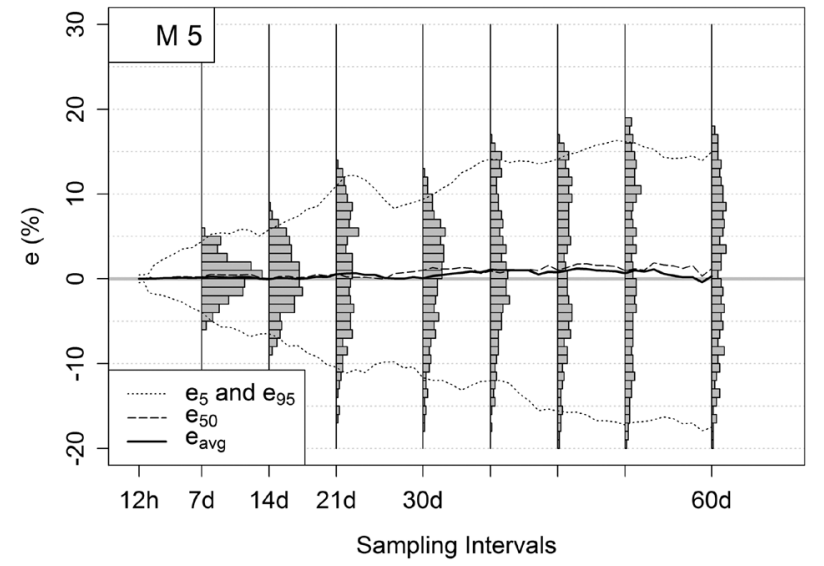

Figure 1. Distribution of uncertainties (or error, e) for the estimation of the annual flux (M5) of the Lestolet watershed (Birgand et al., 2010) in 2002-2003 as a function of sampling interval expressed in days. Vertical histograms represent the distribution of uncertainties for sampling intervals corresponding to the vertical line abscises.

\section{Calculating a Hydrological Reactivity Index}

Several sampling strategy studies have reported that the error ranges increase as watersheds become smaller and "flashier" (e.g., Rekolainen et al., 1991; Kronvang and Bruhn, 1996; Coynel et al., 2004). Results presented in Birgand et al. (2010) show, however, no obvious correlation between precision limits and watershed sizes for nitrate and for the watershed size range tested in Brittany.

Rainfall events that generate significant flow and concentration variations are relatively rare, yet they generate the majority of the annual flow volume and nitrate flux in many cases (e.g., fig. 2). Because they are rare, the probability that they may not be sampled in common time-proportional sampling schemes is high, and larger errors would tend to be made in watersheds for which a larger proportion of annual flow and flux occurs during these rare hydrological events. Moatar and Meybeck (2007) and Moatar et al. (2009) have successfully tested this hypothesis by correlating the precision limits obtained for a given sampling frequency to a hydrological reactivity index, which they called $V_{2} \%$.

The same index is used in this article. This indicator corresponds to the proportion of the annual flow volume that occurs in $2 \%$ of the time corresponding to the highest flow rates (Moatar and Meybeck, 2007). This is obtained by sorting the flow rate values in decreasing order, by calculating the corresponding cumulative flow volume, by extracting the cumulative flow volume value corresponding to the second time percentile (cumulative frequency of occurrence) of the sorted flow rate distribution, and by dividing it by the total annual flow volume and multiplying by 100 to express the value as a percentage (fig. 2).

In the example plotted in figure $2 \mathrm{~b}$, the values for $V_{2} \%$ for 2002-2003 for the artificially drained watersheds Pigeon Blanc and Ville au Chef were $18.5 \%$ and $23 \%$, respectively, while they were quite a bit lower for most of the other watersheds (undrained), such as 10\% for the Lestolet watershed.

\section{RESUlTS}

\section{VARIABILITY OF THE HydROLOGICAL REACTIVITY INDEX}

The hydrological reactivity index is by definition dependent on the hydrological regime in each watershed. Rainfall 

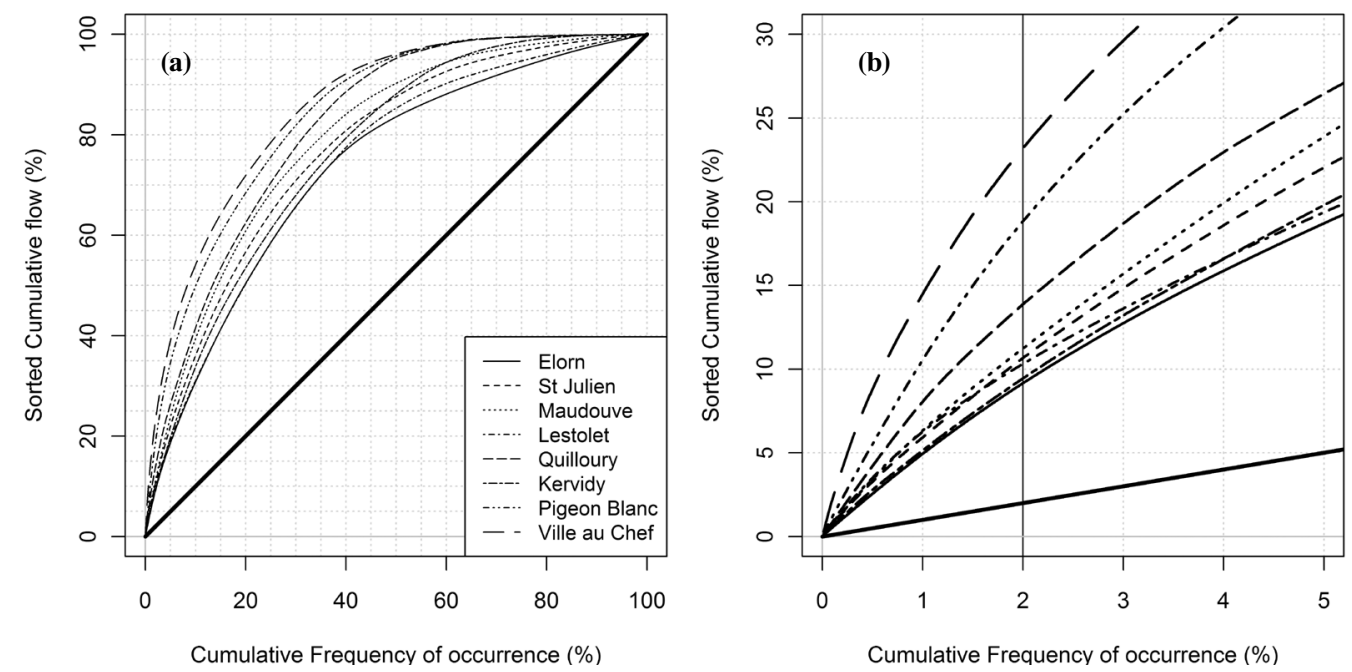

Figure 2. (a) Sorted cumulative annual flow as a function of the cumulative probability of occurrence, and (b) same figure to show the lower values of frequency of occurrence for the studied watersheds in 2002-2003.

variability between years is thus reflected in the $V_{2} \%$ values for a same watershed. For example, the index values varied from just $6 \%$ to over $14 \%$ for the Elorn watershed over the 13 years of available data (fig. 3 ). The higher the index value, the flashier or the more hydrologically reactive the watershed was. Most values were between $5 \%$ and $15 \%$. The two drained watersheds (Pigeon Blanc and Ville au Chef) had the highest index values, greater than $18 \%$, except for one year. In $2000-2001, V_{2} \%$ only reached $10.2 \%$ for the Pigeon Blanc watershed. That year was extremely wet, and high flow lasted for extended periods, which diminished the proportion of the cumulative flow occurring in $2 \%$ of the time compared to the other years. Aside from this particular year, it seems that the drained watersheds were flashier than the others, although one high value $(19.7 \%)$ was recorded for the undrained Stimoës watershed (fig. 3).

\section{Correlation Between Precision limits and HYDROLOGICAL REACTIVITY INDEX}

The precision limits $\mathrm{e}_{5}$ and $\mathrm{e}_{95}$ found for all watershedyears for the annual load and the five concentration indicators

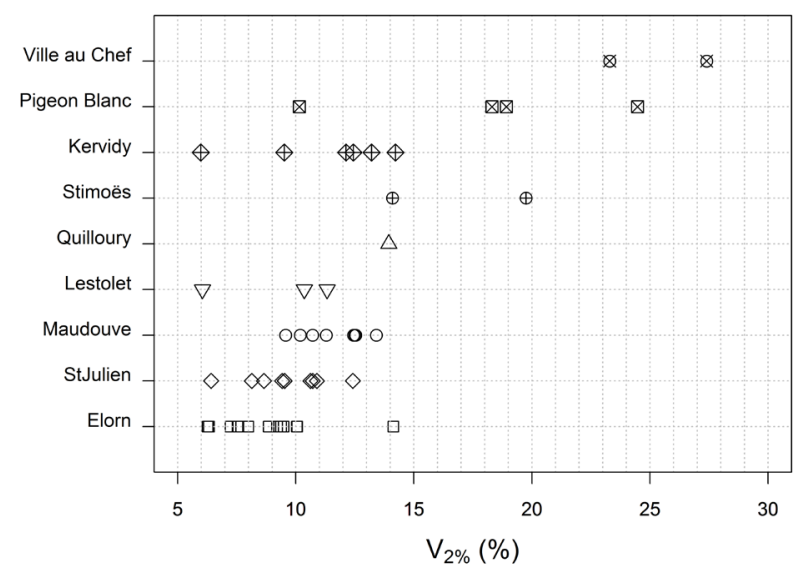

Figure 3. Variability of the hydrological reactivity index $V_{\mathbf{2} \%}$ (percentage of the annual cumulative flow occurring in $2 \%$ of the time corresponding to the highest flow) between watersheds. Each line corresponds to a watershed, and each symbol corresponds to a year of data. were plotted for each sampling interval as a function of the hydrological reactivity index (results of bimonthly and monthly sampling shown in figs. 4 and 5 , respectively). Regressions were found to be significant $\left(\mathrm{r}^{2}>0.75\right)$ between $\mathrm{e}_{5}$ and $e_{95}$ and $V_{2} \%$ for all sampling intervals for the flux estimator, between $e_{95}$ and $V_{2 \%}$ only for both the average $\left(C_{\text {avg }}\right)$ and the median $\left(C_{50}\right)$ concentration estimator, and between $\mathrm{e}_{5}$ and $V_{2 \%}$ only for $C_{\max }$ and the 90 th $\left(C_{90}\right)$ and 95 th $\left(C_{95}\right)$ concentration percentile indicators (figs. 4 and 5). Visual analysis of figures 4 and 5 would suggest that a regression would be significant between $\mathrm{e}_{5}$ and $C_{50}$ and between $\mathrm{e}_{95}$ and $C_{90}$ and $C_{95}$. However, analyses performed on all sampling intervals showed that the correlations were actually not significant, and figures 4 and 5 only display particular cases corresponding to bimonthly and monthly sampling.

The lack of correlation between $\mathrm{e}_{5}$ and $C_{\mathrm{avg}}$ and $C_{50}$ and between $e_{95}$ and $C_{90}$ and $C_{95}$ implied that the precision limits were not dependent on $V_{2 \%}$. In these cases, and to extrapolate the level of uncertainties across all $V_{2} \%$ values, the medians of the precision limit values were calculated (horizontal lines in figs. 4 and 5). The $\mathrm{e}_{95}$ values are not presented in the $C_{\max }$ charts (figs. 4 and 5) because they were all close to zero, as expected. The best regression scheme for $C_{\max }$ was found to be quadratic (figs. 4 and 5).

The significance levels of the regressions are plotted as $\mathrm{r}^{2}$ in the lower part of figure 6 . The values of $\mathrm{r}^{2}$, except for $C_{\max }$, are in most cases well above 0.80 , which warrants the use of a linear regression for analysis here. The regressions, however, are not as good for sampling intervals of less than five days, as the $\mathrm{r}^{2}$ values fall well below 0.80 . This result is expected because the slope of the regression coefficient becomes very small for these sampling intervals, hence decreasing the $r^{2}$ values. In the upper part of figure 6 , the square roots of the regression residuals are plotted when regression was significant, together with the standard deviations of the median values of the uncertainty limits when no significant correlations were found. This upper part of figure 6 shows that the scatter around the general prediction of the uncertainty level increases with increasing sampling intervals. The scatter is represented by the square root of the variance of the regression residuals when there was a signifi- 

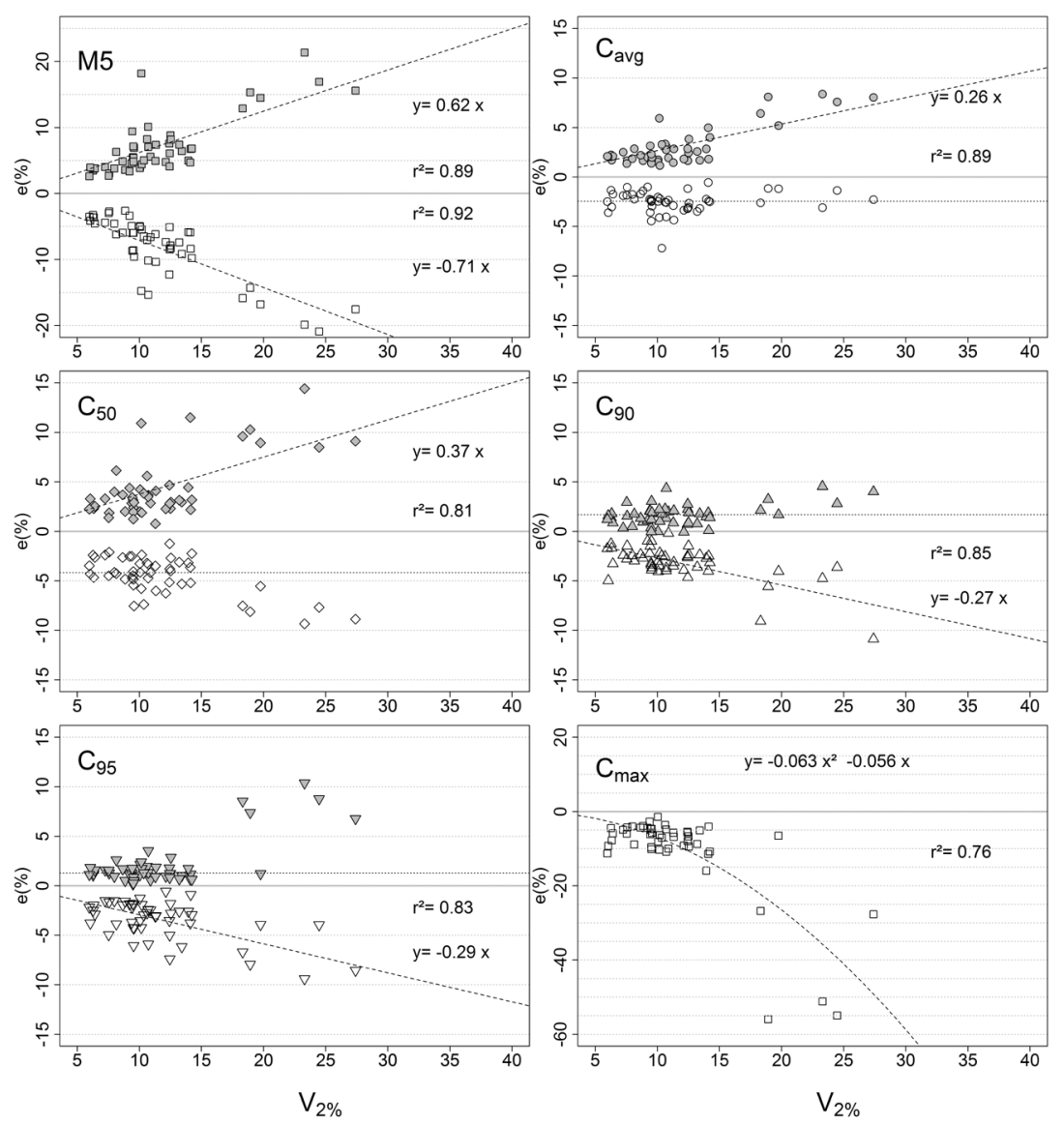

Figure 4. Evolution of the $e_{5}$ and $e_{95}$ values (in black and gray, respectively) of the annual load (M5) and concentration indicators as a function of the hydrological reactivity index for all watersheds and all years, for bimonthly sampling.

cant correlation and by the standard deviation around the median when there was no significant correlation.

The magnitude of the scatter still warrants the use of the regression method as a way to generalize the level of uncertainty for all sampling intervals and all water quality indicators. For $C_{\max }$, the significance level of the quadratic regressions were not as good, with $\mathrm{r}^{2}$ being less than 0.8 for sampling intervals less than 30 days and the square root of the regression residuals being between 7 and 8 for most sampling intervals. Although the quadratic regression was significant, this suggests that the maximum concentrations were only loosely correlated to watershed hydrological reactivity. In addition, for $V_{2} \%$ above $15 \%$, large residuals were observed (data not shown). This corresponds to the two artificially drained watersheds in which there were concentration peaks during flow peaks in the fall and sometimes in the spring (Birgand et al., 2010). The concentration maxima occurred during these very rare peaks, which rendered the chance to sample them minimal, and greatly increased the magnitude of their underestimation compared to the other watersheds. These two main factors may explain the poorer regression results for $C_{\max }$.

The significant correlations derived between the precision limits and the hydrological reactivity index were found to be particularly interesting because the uncertainty level could be estimated from a dimensionless indicator, which allows comparison among watersheds of very different physical characteristics. Moreover, this suggests that uncertainty levels are much less correlated to physical dimension-bound pa- rameters than to the hydrological reactivity of the watersheds, which can be expressed as a dimensionless parameter.

\section{Deriving Sampling Frequency Charts for Nitrate}

In watersheds such as those of our reference datasets for which long-term and frequent water quality data exist, simulations of different frequencies can be conducted and the results can be used to derive guidelines on optimum sampling frequencies for a desired uncertainty of the water quality indicators. However, there would be little incentive to derive these values for these reference watersheds, since high temporal resolution data are already available. It becomes particularly interesting, however, to extrapolate the results obtained for the reference datasets to other watersheds in the region, especially those (the majority of them) for which no long-term or high temporal resolution water quality data are available.

The correlations between precision limits $\mathrm{e}_{5}$ and $\mathrm{e}_{95}$ and the reactivity index shown in figures 4 and 5 are interesting because $V_{2} \%$ can be easily calculated for a watershed where continuous flow data are available (see the Method section). Using the correlation values, it becomes possible to predict the level of uncertainty for the annual flux and concentration indicators for any sampling frequency, since the regressions were calculated for all sampling intervals ranging from 2 to 60 days. This would be limited, however, to watersheds that exhibit similar nitrate dynamics as those of the reference watersheds. 

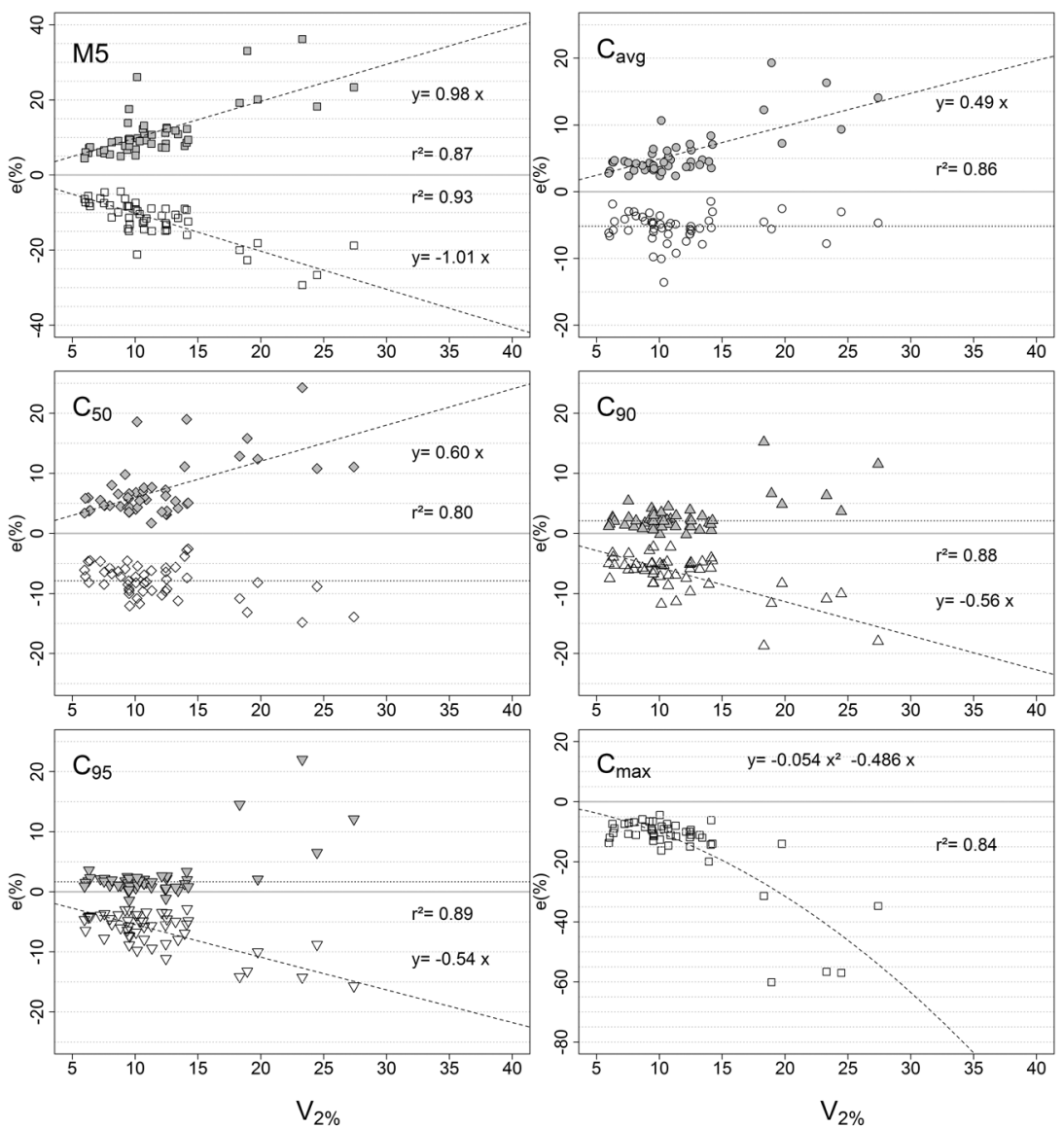

Figure 5. Evolution of the $\mathrm{e}_{5}$ and $\mathrm{e}_{95}$ values (in black and gray, respectively) of the uncertainties of the annual load (M5) and concentration indicators as a function of the hydrological reactivity index for all watersheds and all years, for monthly sampling.
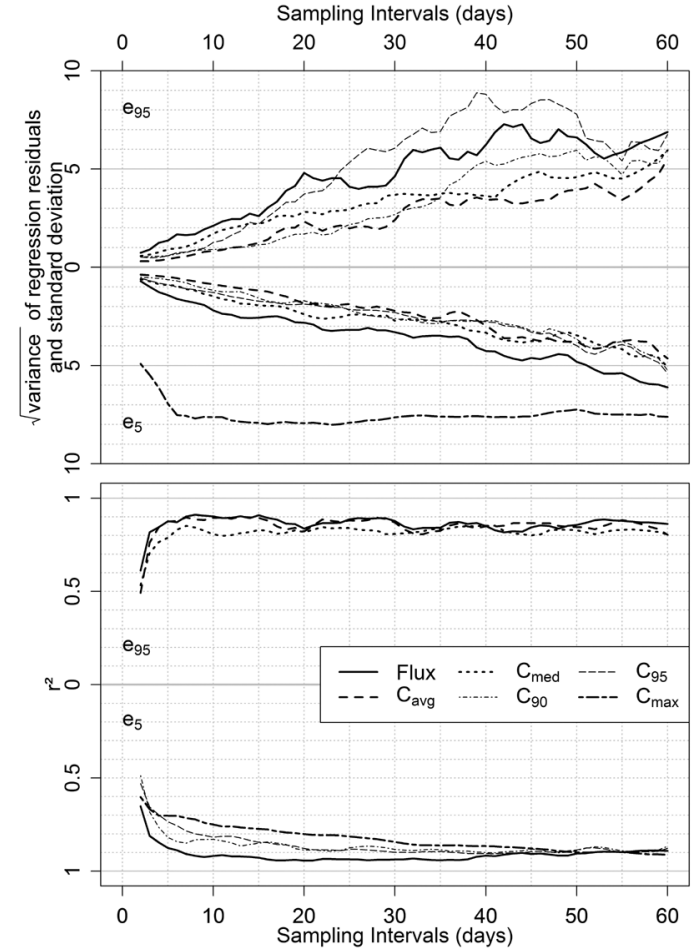

Figure 6. Indicators of significance of the correlations (details in text) between the upper $\left(e_{95}\right)$ and lower $\left(e_{5}\right)$ precision limits and the flow duration indicator $\left(V_{\mathbf{2}}\right)$ for all water quality indicators and for sampling intervals ranging from 2 to 60 days.
Using the regression analysis, it was possible to create a unique relationship between an uncertainty level, a sampling interval, and a hydrological reactivity value. This unique relationship was used to derive the sampling frequency charts shown in figure 7 . The figure shows such charts for flux, $C_{\mathrm{avg}}$, $C_{50}, C_{90}, C_{95}$, and $C_{\max }$ for five levels of uncertainty ranging from $\pm 5 \%$ to $\pm 25 \%$. In each graph in figure 7 , the $y$-axis is represented with opposite directions so that the guideline curves derived from regression on both $\mathrm{e}_{5}$ and $\mathrm{e}_{95}$ could be drawn in the same graph. The curves derived from $\mathrm{e}_{5}$ and $\mathrm{e}_{95}$ are represented in the lower and upper parts of the graphs, respectively. When the medians were calculated for several of the concentration indicators, the guidelines appear as horizontal lines corresponding to the sampling frequency and for a given imprecision level.

For $C_{90}$ and $C_{95}$, additional lines corresponding to overestimations of $+1 \%$ to $+3 \%$ have been added on the $\mathrm{e}_{95}$ side because the other curves were out of range. For these two concentration indicators, the horizontal lines were drawn for $V_{2} \%$ values lower than $15 \%$ because the e95 values were well represented by the medians only when $V_{2} \%$ was less than $15 \%$ (e.g., figs. 4 and 5). For $V_{2 \%}$ values greater than $15 \%$, the precision limit of the overestimation ( $\mathrm{e}_{95}$ ) for both $C_{90}$ and $C_{95}$ varied widely and could not be predicted in this analysis. This corresponded to watersheds for which concentration peaks were observed in conjunction with flow peaks in some of the fall and spring events (drained watersheds). The actual 90th and 95th concentration percentiles were not associated with these peaks, but the probability of sampling during these 

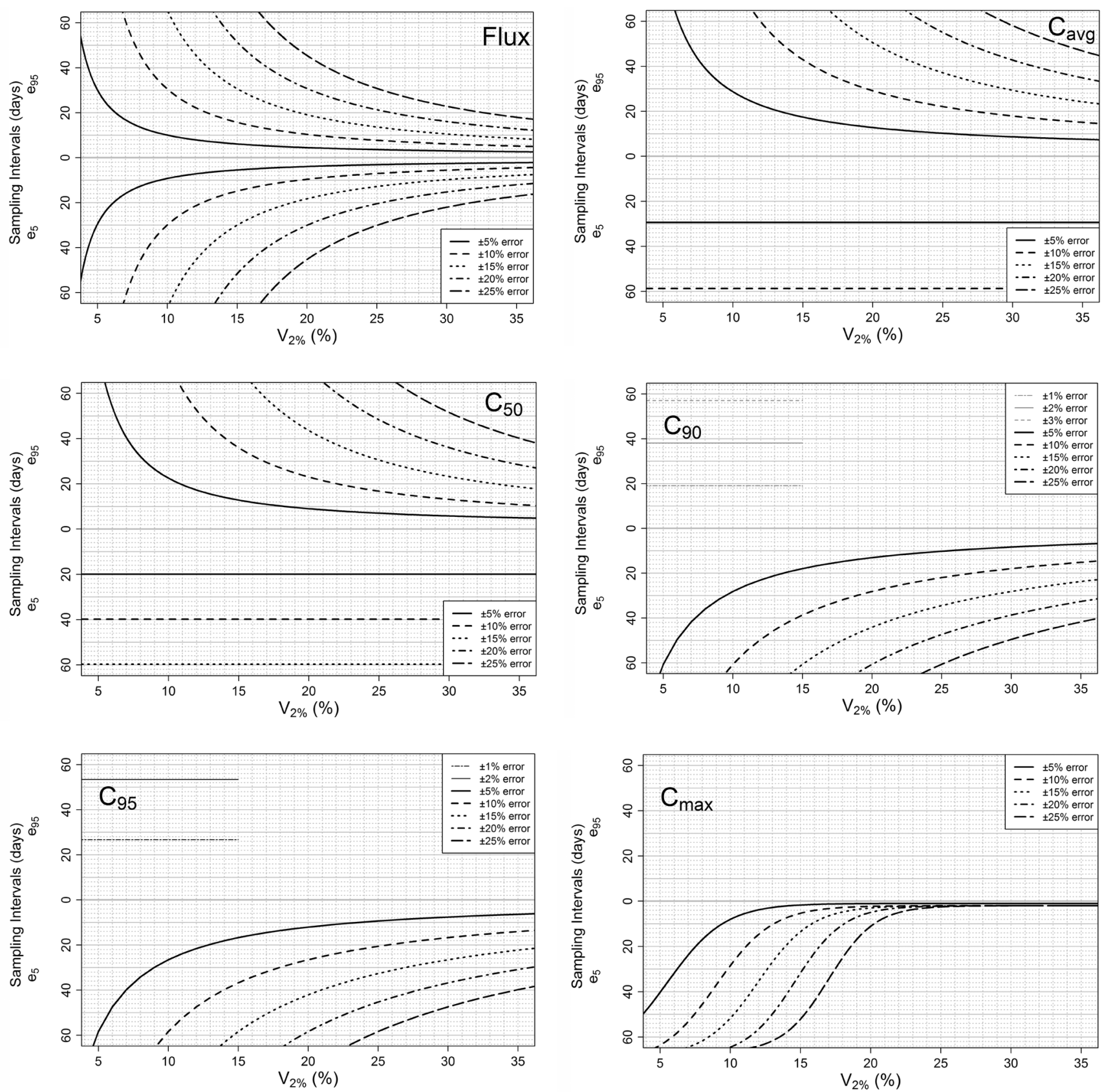

Figure 7. Sampling frequency charts to calculate the minimum water sampling intervals corresponding to a desired uncertainty level and for a given hydrological reactivity $\left(V_{2} \%\right)$ of a watershed. Curves derived for water quality indicators include the annual load (flux), annual arithmetic average $\left(C_{\text {avg }}\right)$, median $\left(C_{50}\right), 95$ th and 90th percentiles $\left(C_{95}\right.$ and $\left.C_{90}\right)$, and $C_{\max }$ concentration indicators.

events was not negligible and the estimators could largely overestimate the actual indicator values. In these cases, the estimated 90th and 95th percentiles could be largely overestimated compared to the actual values, hence the high and variable values displayed in figures 4 and 5 and the truncated lines in the corresponding charts in figure 7.

The sampling frequency charts can be used as follows: a watershed manager in Brittany would like to measure nitrate annual fluxes at the outlet of a given watershed with a maximum uncertainty induced by infrequent sampling of $\pm 10 \%$. The watershed has a relatively average hydrological reactivity in general, and the upper values of the percentage of flow occurring in $2 \%$ of the time corresponding to the highest flow are around $10 \%\left(V_{2 \%}=10 \%\right)$. In the flux chart in figure 7 , the values corresponding to $V_{2} \%=10 \%$ and an uncertainty level of $\pm 10 \%$ yield sampling intervals of 30 days, whether this result is obtained from the curves generated by regression on $\mathrm{e}_{5}$ or on $\mathrm{e}_{95}$. The manager will then opt for monthly sampling in this particular watershed and for the given uncertainty level. The same analysis for a much more reactive watershed (e.g., $V_{2 \%}=25 \%$, a partially drained watershed, for example), would impose weekly sampling at a minimum.

Figure 7 suggests that among all indicators, $C_{\max }$ would impose the highest sampling frequency, closely followed by the flux indicator. Much larger sampling intervals would yield the same uncertainty level for the other concentration indicators. The dissymmetry of the graphs of figure 7 results from the fact that overestimation of a water quality indicator 
$\left(e_{95}\right)$ was never found to be equal to the underestimation $\left(e_{5}\right)$ for a given sampling frequency (e.g., figs. 4 and 5). Dissymmetry is small for the flux chart. For the other indicators, however, a strong dissymmetry can be observed. This is due to the fact that the $\mathrm{e}_{95}$ values, and not the $\mathrm{e}_{5}$ values, are linked to $V_{2 \%}$ for $C_{\text {avg }}$ and $C_{50}$, while the opposite is true for $C_{95}$ and $C_{90}$. As said before, the $C_{\max }$ graph can only be dissymmetrical because $C_{\max }$ can only be underestimated. The sigmoidal shape of the curves for $C_{\max }$, which differs from the logarithm shape of the other indicator curves, is a result of the difference in the type of regression used (quadratic versus linear) between $\mathrm{e}_{5}$ and $V_{2} \%$ for this indicator. All curves were only slightly smoothed from the empirical data using regression best fit.

\section{BIAS AND HydRologicAl REACTIVITY INDEX}

In the accompanying article (Birgand et al., 2010), bias values were found to be linearly correlated with sampling intervals. Analysis done on bias for bimestrial sampling, shown in figure 8 , can thus be linearly interpolated to any other sampling interval.

The flux estimator, despite being the algorithm that induced the least bias (Birgand et al., 2010), appears to be positively biased with increasing watershed hydrologic reactivity (fig. 8). A polynomial regression was attempted (bias = $0.016 V_{2 \%}{ }^{2}-0.0068 V_{2 \%}$ ) for this estimator, which suggests that for a highly reactive watershed $\left(V_{2 \%}=26 \%\right)$, the bias on bimestrial sampling can reach $+10 \%$, hence $+5 \%$ for monthly
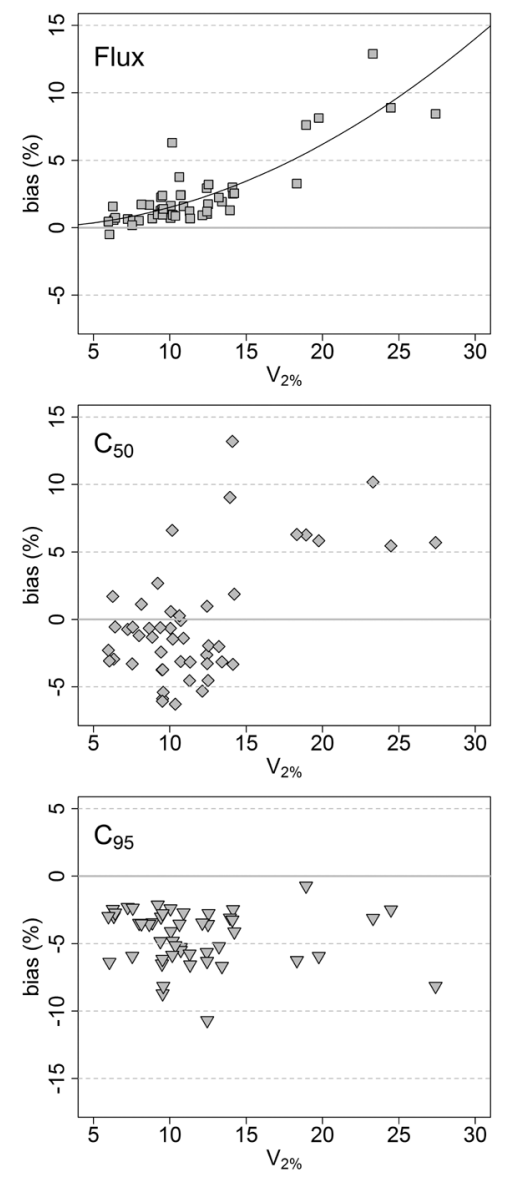

Figure 8. Bias values of the flux, $C_{\text {avg }}, C_{50}, C_{90}, C_{95}$, and $C_{\max }$ estimators as a function of the watershed hydrological reactivity index ( $V_{2 \%}$ ). Values obtained from bimestrial sampling simulations for all 50 watershed-years.
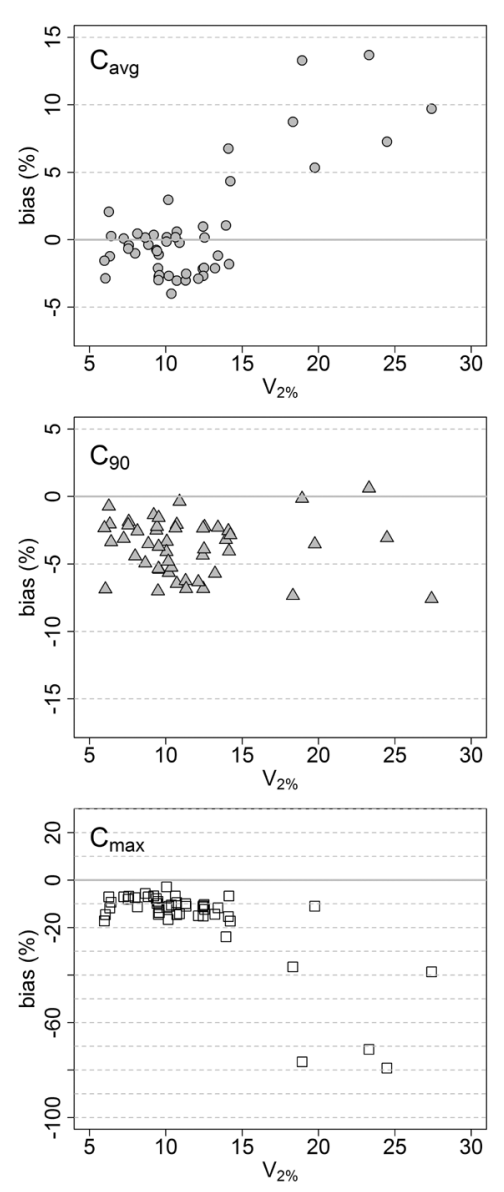

sampling. Although the bias is not null or negligible in this case, it remains that for most watersheds and for most years in Brittany $\left(V_{2} \%<15 \%\right)$ the bias on flux estimators is low, even for bimestrial sampling using the M5 algorithm (Birgand et al., 2010). Interestingly, the finding of positive bias of the flux estimator is opposite to that found by Moatar and Meybeck (2007). This is due to the nearly systematic dilution effect of the nitrate concentrations during hydrological events in our case, and the opposite effect for the particlebound nutrients of study in Moatar and Meybeck (2007).

Figure 8 suggests that for $V_{2} \%<14 \%$, the estimators of $C_{\text {avg }}$ and $C_{50}$ are not biased or are slightly negatively biased, while for watersheds for which $V_{2 \%}>14 \%$, they are positively biased and to a larger extent. This suggests overall that as the watersheds become more hydrologically reactive, the chances to overestimate rather than underestimate $C_{\text {avg }}$ and $C_{50}$ are higher and the magnitude of the overestimation is higher in absolute value than that of the underestimation.

The 90th and 95th percentile concentration indicators are very seldom overestimated, and the magnitude of this overestimation is below 3\% even for bimestrial sampling (fig. 7). As expected, both indicators are negatively biased, although the bias remains relatively small (of the order of 5\% for bimestrial sampling; fig. 8) and does not seem to be correlated with watershed hydrological reactivity.

The negative bias for $C_{\max }$ does not seem to be correlated to hydrological reactivity for $V_{2} \%<15 \%$. For higher $V_{2} \%$ values, bias seems to increase with the flashiness index. The lat- 
ter values correspond to the two artificially drained watersheds in which there were concentration peaks during flow peaks in the fall and sometimes in the spring (Birgand et al., 2010). The concentration maxima occurred during these very rare peaks, which rendered the chance to sample them minimal and increased the magnitude of their underestimation much more so than for the other watersheds, hence the higher bias.

\section{DisCUSSION}

Uncertainties associated with measuring water quality indicators result from the combination of uncertainties at all steps of the monitoring process. They include uncertainties in measured flow rates and volume, uncertainties induced by infrequent sampling and the calculation algorithm for the flux estimates, uncertainties caused by the actual location of the intake in the water column, uncertainties caused by sample degradation between sampling and analysis, and uncertainties during laboratory analyses (reviewed in part by Harmel et al., 2006, and Rode and Suhr, 2007). Quantifying the relative importance of each uncertainty component has been attempted by Harmel et al., (2006) in plot-scale watersheds and at the event scale. De Vries and Klavers (1994) suggested that in large watersheds (i.e., the Rhine and Meuse rivers in The Netherlands) and in the case of less than weekly sampling, infrequent sampling may induce much larger errors than the uncertainties in the concentration and flow rate values for ammonium, total suspended solids, and chloride annual fluxes. To confirm these results, further work is needed for a variety of conditions to quantify the relative importance of each uncertainty component.

A first step is to evaluate the uncertainties induced by infrequent sampling, as uncertainty levels have been shown to vary widely as a function of sampling frequency, but also among watersheds and years for a set frequency (e.g., Birgand et al., 2010). Harmonized uncertainty levels in water quality monitoring networks would make for reliable water quality indicators and for better and more meaningful comparisons between stations and between years of monitoring. To our knowledge, the sampling frequency charts presented in this article are the first of their kind to provide guidelines on sampling frequencies for a desired uncertainty level as a function of hydrological regime in watersheds.

\section{Precaution when Using the Sampling Frequency Charts}

The sampling frequency charts provide an objective framework to compare uncertainty values for nitrate indicators found in watersheds with size varying by nearly two orders of magnitude. Errors found in the $4 \mathrm{~km}^{2}$ watershed can be objectively compared to the errors found in the $252 \mathrm{~km}^{2}$ watershed through the prism of the dimensionless hydrological reactivity index first proposed by Moatar and Meybeck (2007). The method also shows that hydrological reactivity plays a major role in the generation of uncertainty in flux and concentration indicators, at least in Brittany. This probably applies to some extent elsewhere and for other nutrients, and we suggest that future studies reporting uncertainties associated with time-proportional sampling should include a metric of hydrological reactivity.
The sampling frequency charts in figure 7 must be used with caution. The first caution is that the flashiness index $\left(V_{2} \%\right)$ varies from year to year, as shown in figure 3 . In the Elorn watershed for which 13 years of data were available, $V_{2 \%}$ varied most years between $6 \%$ and $10 \%$, reaching $14 \%$ in one particularly dry year. This variability must be taken into account when designing a sampling scheme. The upper value of the recorded $V_{2 \%}$ should be preferentially chosen when using the charts to minimize uncertainty levels.

The second caution is that the sampling frequency charts were derived from linear and quadratic regressions for which the residuals are sizable (fig. 6). In most cases, the quality of the regressions decreased with increasing sampling intervals. The curves are thus not as reliable for large sampling intervals (e.g., above 35 day intervals).

The third caution is that the charts were derived using $\mathrm{e}_{5}$ and $e_{95}$, which means that the assumption was made that the $90 \%$ confidence interval was an appropriate interval to characterize the uncertainties in the water quality indicators induced by infrequent sampling. Had $95 \%$ or $80 \%$ values been chosen as the confidence interval to characterize the uncertainties, the charts would have been different and sampling interval recommendations would have been more stringent or more lenient, respectively, compared to the results presented here. Sampling frequency charts presented by Birgand et al. (2009) corresponding to the $95 \%$ confidence intervals confirm this.

The fourth caution is that the charts only represent the general tendency for nitrate exhibiting concentration dilution during flow peaks in this region of the world. It is believed that these dynamics are probably widespread in Brittany (see below). However, it is unclear whether these curves can be used in regions of the world other than that from which they were derived. It is also unclear whether they could also be applied to much smaller (plot scale, e.g., less than $1 \mathrm{~km}^{2}$ ) or much larger (e.g., over $1000 \mathrm{~km}^{2}$ ) watersheds, although the method does not theoretically depend on watershed size.

\section{The Role of Nitrate Concentration Variations in UNCERTAINTY LEVELS}

This analysis shows that there is a strong correlation between uncertainty levels and hydrological reactivity. This suggests that the level and the variability of nitrate concentrations are of lesser importance than the hydrological variability. This is particularly interesting because nitrate concentrations were quite variable and exhibited strong dilution effect during flow peaks (fig. 9; Birgand et al., 2010). However, during winter when most of the nitrate losses occur, concentrations decreased by $20 \%$ to $40 \%$ during flow peaks, while the flow values were multiplied by $200 \%$ to $500 \%$. The result was that load values and variations were still very much correlated to flow variations and that concentration variations were largely dampened at these times. The levels (e.g., concentration average) and dynamics (e.g., extent of the nitrate troughs during flow peaks) of the nitrate concentrations did, however, vary from year to year and from watershed to watershed (fig. 9). It is probable that the scatter of uncertainty points observed around the general correlation with $V_{2 \%}$ (e.g., figs. 4 and 5) resulted in part from the differences in the nitrate dynamics among watersheds.

The many studies that have been published on the seasonal nitrate concentration pattern in Brittany streams and rivers suggest that in most cases, although not always, concentra- 
tions tend to be higher in winter and lower in summer (e.g., Gascuel-Odoux et al., 2010; Molénat et al., 2002, 2008; Guillaud and Bourriel, 2007; Martin et al., 2004; Ruiz et al., 2002). To our knowledge, there have been very few reports that specifically study the nitrate dynamics at the event basis over time in Brittany. It has been shown for a few events that nitrate concentrations may exhibit troughs during flow peaks (e.g., Cann, 1998). This relationship has also been found by Molénat et al. (2008), Martin et al. (2004), and Ruiz et al. (2002), although it has not been reported as a specificity in these studies. The main reason for this is probably the coarse time resolution of the available data, which was monthly most of time and daily at best. Having access to hourly data over long periods of time for this study revealed short-term dynamics that could not have been analyzed in the past. Yet these short-term variations have a great impact on the level of uncertainties.

To derive the charts, we made the implicit assumption that most watersheds in Brittany would exhibit similar nitrate dynamics with flow as those of the reference dataset. It cannot be absolutely proven that the reference watersheds are a representative sample of most watersheds in Brittany, but in light of the reports cited above there is no reason to believe that they would be dramatically different, since nitrate pollution is widespread in Brittany. Hence, we believe that the charts could be widely used in Brittany. Interestingly the quasi-systematic short-term dilution of concentrations during flow peaks is not at all in con- tradiction with the seasonal patterns (e.g., fig. 9). In the reference watersheds dataset, the seasonal patterns were found to generally follow those of the reports previously mentioned, as most watersheds showed a slight or no concentration increase in winter, and only one (Maudouve) showed higher concentrations in summer than in winter (e.g., fig. 9).

It is expected that the general level of nitrate export load will eventually decrease following the widespread implementation of BMPs in Brittany. This will likely lower the concentration values but will not dramatically change the dilution effect dynamics observed until the groundwater nitrate concentrations decrease dramatically. The charts are thus likely to remain valid for probably the next decade (a safe assumption, since the current rate of water quality improvement seems to be quite slow at best).

It is likely that the charts could be used in watersheds where a systematic concentration dilution effect is observed during flow peaks because of the dampening effect of flow on concentrations, although this must be verified. It is unclear, however, whether the results would change in watersheds for which a significant number of hydrological events (more than $20 \%$ of them, e.g., in artificially drained watersheds) exhibit nitrate concentration peaks during flow peaks. It is fair to say that, in all cases, the charts cannot be used for any other nutrient or pollutant. The method should thus be applied in other places in the world and for other nutrients to evaluate how the results hold across a range of conditions.
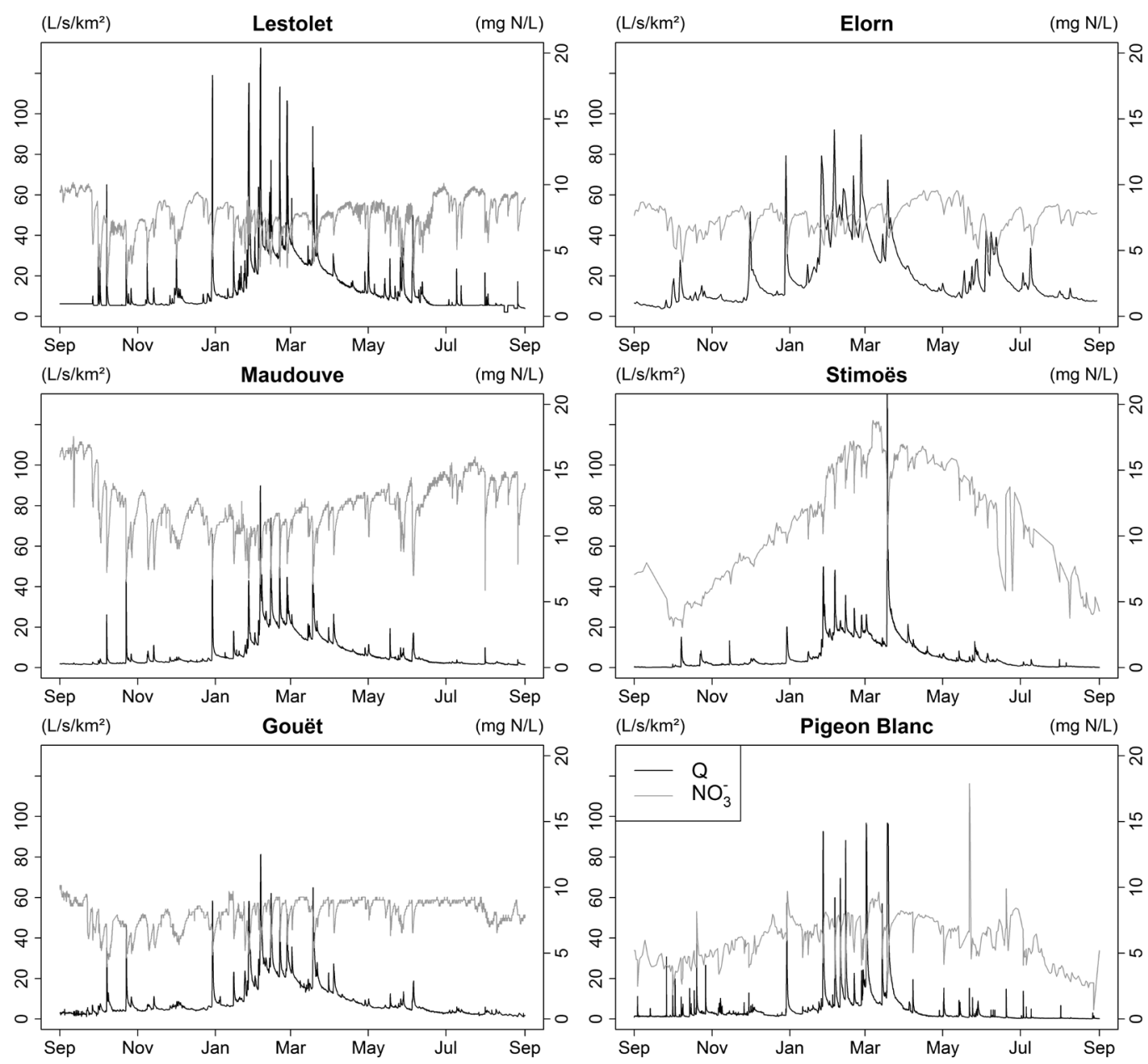

Figure 9. Nitrate and flow dynamics for six of the reference watersheds in year 2001-2002. 
Table 1. Expected uncertainty range when estimating annual nitrate flux and concentration indicators for

three common sampling frequencies in Brittany, France. Uncertainties are given for the two watershed hydrological reactivity values $\left(V_{2} \%\right)$ between which most reactivity values were included.

\begin{tabular}{|c|c|c|c|c|c|c|}
\hline & \multicolumn{2}{|c|}{ Bimonthly Sampling } & \multicolumn{2}{|c|}{ Monthly Sampling } & \multicolumn{2}{|c|}{ Bimestrial Sampling } \\
\hline & $V_{2 \%}=6 \%$ & $V_{2 \%}=14 \%$ & $V_{2 \%}=6 \%$ & $V_{2 \%}=14 \%$ & $V_{2 \%}=6 \%$ & $V_{2 \%}=14 \%$ \\
\hline Flux & $-4 \%$ to $+4 \%$ & $-9 \%$ to $+9 \%$ & $-6 \%$ to $+6 \%$ & $-14 \%$ to $+14 \%$ & $-8.5 \%$ to $+8.5 \%$ & $-20 \%$ to $+20 \%$ \\
\hline$C_{\text {avg }}$ & $-2.5 \%$ to $+1 \%$ & $-2.5 \%$ to $+4 \%$ & $-5 \%$ to $+2.5 \%$ & $-5 \%$ to $+7.2 \%$ & $-10 \%$ to $+5 \%$ & $-10 \%$ to $+11.5 \%$ \\
\hline$C_{50}$ & $-3.5 \%$ to $+1.2 \%$ & $-3.5 \%$ to $+5 \%$ & $-7.5 \%$ to $+2.9 \%$ & $-7.5 \%$ to $+8 \%$ & $-15 \%$ to $5.3 \%$ & $-15 \%$ to $+12.5 \%$ \\
\hline$C_{90}$ & $-1.8 \%$ to $+0.7 \%$ & $-4 \%$ to $+0.7 \%$ & $-3.3 \%$ to $+1.6 \%$ & $-7.5 \%$ to $+1.6 \%$ & $-6 \%$ to $+3.1 \%$ & $-14 \%$ to $+3.1 \%$ \\
\hline$C_{95}$ & $-1.7 \%$ to $+0.5 \%$ & $-4 \%$ to $+0.5 \%$ & $-3.3 \%$ to $+1.1 \%$ & $-12.8 \%$ to $+1.1 \%$ & $-6.1 \%$ to $+2.2 \%$ & $-14.2 \%$ to $+2.2 \%$ \\
\hline$C_{\max }$ & $-3 \%$ & $-14 \%$ & $-5 \%$ & $-17 \%$ & $-10 \%$ & $-37 \%$ \\
\hline
\end{tabular}

\section{EXPECTED ERROR RANGE FOR Nitrate FLUX AND CONCENTRATION INDICATORS IN BRITTANY}

In the accompanying article (Birgand et al., 2010), no definite uncertainty ranges could be reported because the preliminary results were not obtained through the prism of the hydrological reactivity index analysis. This analysis is possible in this article. Most of the $V_{2} \%$ values among the 50 watershed-year datasets vary between $6 \%$ and $14 \%$ (fig. 3). Using this range of $V_{2} \%$ values in the sampling frequency charts (fig. 7), it is possible to draw conclusions about the error range expected due to infrequent sampling while estimating nitrate flux and concentration indicators in Brittany. The values of the uncertainty ranges for three common sampling frequencies are summarized in table 1 .

For monthly and bimestrial sampling, errors in the annual arithmetic average concentration may be relatively limited, since they may vary between $-5 \%$ and $+2.5 \%$ to $+7.2 \%$ and between $-10 \%$ and $+5 \%$ to $+11.5 \%$, respectively, whether the watershed is less or more hydrologically reactive (table 1 ). The range of errors is thus relatively small even for bimestrial samples, confirming the general perception, although never fully proven until now, that the annual average nitrate concentrations were generally reliable in Brittany water quality monitoring stations. For flux estimations, the uncertainty tends to be higher than for $C_{\text {avg }}$. For monthly sampling, uncertainties may vary between $\pm 6 \%$ and $\pm 14 \%$ (for $V_{2} \%$ equal to $+6 \%$ and $+14 \%$, respectively; table 1 ), while for bimestrial sampling errors may vary between $\pm 8.5 \%$ and $\pm 20 \%$ (for $V_{2} \%$ equal to $+6 \%$ and $+14 \%$, respectively). The range of errors varies greatly according to small changes in the $V_{2 \%}$ values, thus undermining all attempts to summarize error ranges in one overall lower and one overall upper limit. The sampling frequency charts may now serve as a reference instead. The uncertainty for the other concentration indicators is of the same order as that of the arithmetic average, except for the maximum estimator, where the maximum concentration can be underestimated up to $37 \%$ when sampling on a bimestrial basis.

The uncertainty levels reported here only concern the uncertainties due to infrequent sampling. The actual uncertainty levels should be expected to be higher because of all the other sources of uncertainty. In light of the work of de Vries and Klavers (1994), who attempted to quantify the relative importance of sources of uncertainties for similar sampling conditions, it is possible that the overall uncertainties are actually quite similar to the values reported here.

It should be clear that the uncertainty ranges found are only applicable to annual values. At no time can they be taken to be valid at the event basis, nor at any time period other than yearly, as stated before. For this reason, these results cannot be easily compared to most reports conducted at the plot scale. Wang et al. (2003) used a version of the M3 algorithm (described in Birgand et al., 2010) to simulate error induced by weekly, monthly, and trimestrial sampling on annual nitrate loads leaving 0.1 to 0.4 ha drainage plots. The uncertainty range seemed to increase as the drain spacing decreased, and the values seemed, in the best case of the larger drain spacing, to easily reach $\pm 30 \%$. Although the results were obtained using the M3 algorithm, which we found to be biased (Birgand et al., 2010), the level of uncertainty increase with decreasing drain spacing suggests that their results were probably linked to the different hydrological reactivity. The level of uncertainty is much higher than the values we report in this article, and this is expected in very hydrologically reactive drainage plots.

The uncertainty ranges reported here for nitrate annual fluxes in intermediate-size watersheds are much lower than those commonly reported for parameters associated with total suspended solid (TSS) fluxes in watersheds of all sizes, where the error range may easily reach $\pm 50 \%$ or even higher for monthly sampling (e.g., Walling et al., 1992; Kronvang and Bruhn, 1996; Coynel et al., 2004; de Vries and Klavers, 1994; Moatar and Meybeck, 2007). The relatively low error range for nitrate fluxes is probably due to the dilution effect exhibited by nitrate during flow events (Birgand et al., 2010; Moatar et al., 2009). Indeed, the nitrate dilution effect during flow peaks, compared to the opposite "concentration effect" common in particle-bound or associated pollutants, lowers the importance of the short-lived peak flows in the load calculations. The ranges of errors induced by missing events in the sampling are thus relatively small compared to the ranges expected for particle-bound pollutants.

To our knowledge, this study represents the first time that the uncertainty of concentration indicators has been reported, making any relative comparison difficult. Nonetheless, the absolute values of the uncertainty appear to be relatively small, confirming together with the results for fluxes the relative robustness of the local monitoring network sampling scheme for nitrate in Brittany (usually monthly sampling). This is also probably due to the dilution effect of nitrate concentrations. Most concentration values follow a general baseline that corresponds to the falling limb of the hydrographs and to low flow conditions. The concentrations are only temporarily lowered and rarely lowered by more than $50 \%$ during short-lived events (fig. 9; Birgand et al., 2010). The weight of the short-lived and small concentration troughs in the concentration indicator calculation is thus relatively small, and these indicators mostly represent the concentration behavior outside the flow peaks.

Even though the error ranges for nitrate fluxes in Brittany are relatively small compared to those that have been reported for TSS loads, the errors may still lead to wrong con- 
clusions. For example, in a watershed for which $V_{2 \%}$ equals $10 \%$ two years in a row and in which the flux stays exactly the same during these two years, it would be possible, using monthly sampling, to overestimate the flux by $+10 \%$ in the first year and underestimate it by $-10 \%$ in the second year. This would lead to the wrong conclusion that the flux decreased by about $20 \%$ in two years when in fact it stayed the same. The same analysis could be done for an erroneous increase in flux. Errors induced by monthly sampling are thus not negligible.

Finally, the relatively small uncertainty in nitrate flux and concentration indicators reported in table 1 should not hide other disparities. For the drained and flashy watersheds where $V_{2 \%}$ may reach $25 \%$, the error in estimating annual flux may reach $\pm 25 \%$ and $\pm 37 \%$ for monthly and bimestrial sampling, respectively (fig. 7). For similar conditions, the upper limit of overestimation of the annual average concentration may reach $+13 \%$ and $+21 \%$ for monthly and bimestrial sampling, respectively (fig. 7). Uncertainty of the $C_{\max }$ indicator for such conditions and sampling intervals can reach extremely high values over $100 \%$ (data not shown). Standardized sampling frequency schemes tend to be applied over entire regions or states. Our report suggests that although standardized monthly sampling seems to be generally robust in Brittany for nitrate, local conditions (e.g., artificially drained watersheds) may demand adjustment of the sampling schemes to obtain the same level of uncertainty.

\section{CONCLUSION}

The main objective of this work was to provide tools for watershed managers to optimize sampling frequencies in regional and national water quality monitoring networks. The sampling frequency charts derived in this article provide a first possible tool that can be used to assess uncertainty levels in a particular watershed and to design a sampling frequency scheme for a desired uncertainty level. The strength of the approach lies in the fact that the charts relate uncertainty levels to a non-dimensional hydrological reactivity index, which can be calculated on a year by year and watershed by watershed basis provided that continuous flow records are available. Using this approach, it becomes possible to harmonize water quality networks, not on a common sampling frequency but rather on a common uncertainty level. This would allow for more meaningful comparisons between watersheds and between years and better assessment of short and long term trends in water quality networks.

It is unclear whether the results could be extrapolated to other nutrients and to other parts of the world. The correlation between uncertainty levels and hydrological reactivity suggests that hydrological variability plays a dominant role over nitrate concentration variability in the uncertainty levels. This is related to the observed quasi-systematic nitrate concentration dilution that occurs during flow peaks for nitrate in Brittany. The method should be easily transposed to other regions of the world for which the same nitrate concentration dynamics can be observed. Similar approaches should be tested for other nutrients as well.

\section{ACKNOWLEDGEMENTS}

The authors thank Mrs. A. Bouédo for acquiring and providing to us nitrate quality data of superior quality, without which little of this work could have been done. The authors also thank Eric Le Saos, Pascal Serrand, and Patricia SaintCast, Cemagref field and laboratory technicians of Rennes, France, for their assistance in acquiring data on the partially drained watersheds.

\section{REFERENCES}

Birgand F., C. Faucheux, F. Moatar, and M. Meybeck. 2009. Uncertainties on nitrate water quality indicators associated with infrequent sampling in Brittany, France. ASABE Paper No. 096601. St. Joseph, Mich.: ASABE.

Birgand F., C. Faucheux, G. Gruau, B. Augeard, F. Moatar, and P. Bordenave. 2010. Uncertainties in assessing annual nitrate load and concentration indicators: Part 1 . Impact of sampling frequency and load estimation algorithms. Trans. ASABE 53(2): 437-446.

Cann, C. 1998. Transfert de polluants vers l'eau. In Agriculture intensive et qualité des eaux, 233-247. C. Cheverry, ed. Paris, France: INRA.

Coynel A., J. Schafer, J. E. Hurtrez, J. Dumas, H. Etcheber, and G. Blanc. 2004. Sampling frequency and accuracy of SPM flux estimates in two contrasted drainage basins. Sci. Total Environ. 330: 233-247.

de Vries, A., and H. C. Klavers. 1994. Riverine fluxes of pollutants: Monitoring strategy first, calculation methods second. European Water Poll. Control 4(2): 12-17.

EU. 2000. Directive 2000/60/EC of the European Parliament and of the Council of 23 October 2000 establishing a framework for Community action in the field of water policy. Brussels, Belgium: European Parliament.

Gascuel-Odoux, C., P. Aurousseau, P. Durand, L. Ruiz, and J. Molénat. 2010. The role of climate on inter-annual variation in stream nitrate fluxes and concentrations. Sci. Total Environ. 408(23): 5657-5666.

Guillaud, J.-F., and L. Bouriel. 2007. Relation concentration-débit et évolution temporelle du nitrate dans 25 rivières de la région Bretagne (France). Rev. Sci. Eau 20(2): 213-226.

Harmel, R. D., R. J. Cooper, R. M. Slade, R. L. Haney, and J. G. Arnold, 2006. Cumulative uncertainty in measured streamflow and water quality data for small watersheds. Trans. $A S A B E$ 49(3): 689-701.

Johnes, P. J. 2007. Uncertainties in annual riverine phosphorus load estimation: Impact of load estimation methodology, sampling frequency, baseflow index, and catchment population density. $J$. Hydrol. 332(1-2): 241-258.

Kronvang, B., and J. Bruhn. 1996. Choice of sampling strategy and estimation method for calculating nitrogen and phosphorus in small lowland streams. Hydrol. Proc. 10(11): 1483-1501.

Martin, C., L. Aquilina, C. Gascuel-Odoux, J. Molénat, M. Faucheux, and L. Ruiz. 2004. Seasonal and interannual variations of nitrate and chloride in stream waters related to spatial and temporal patterns of groundwater concentrations in agricultural catchments. Hydrol. Proc. 18(7): 1237-1254.

Moatar, F., and M. Meybeck. 2005. Compared performances of different algorithms for estimating annual nutrient loads discharged by the eutrophic River Loire. Hydrol. Proc. 19(2): 429-444.

Moatar, F., and M. Meybeck. 2007. Riverine fluxes of pollutants: Towards predictions of uncertainties by flux duration indicators. Comptes Rendu Geoscience 339(6): 367-382

Moatar, F., G. Person, M. Meybeck, A. Coynel, H. Etcheber, and P. Crouzet. 2006. The influence of contrasting suspended particulate matter transport regimes on the bias and precision of flux estimates. Sci. Total Environ. 370(2-3): 515-531.

Moatar, F., F. Birgand, M. Meybeck, C. Faucheux, and S. Raymond. 2009. Uncertainties on river water quality metrics 
assessment (nutrients, concentration quantiles, and fluxes) based on discrete surveys. Houille Blanche 3 (June): 68-76 (in French).

Molénat, J., P. Durand, C. Gascuel-Odoux, P. Davy, and G. Gruau. 2002. Mechanism of nitrate transfer from soil to stream in an agricultural watershed of French Brittany. Water Air Soil Pollut. 133: $161-183$.

Molénat, J., C. Gascuel-Odoux, L. Ruiz, and G. Gruau. 2008. Role of water table dynamics on stream nitrate export and concentration in agricultural headwater catchment (France). $J$. Hydrol. 348(3-4): 363-378.

Rekolainen, S., M. Posch, J. Kämäri, and P. Ekholm. 1991. Evaluation of the accuracy and precision of annual phosphorus load estimates from two agricultural basins in Finland. J. Hydrol. 128: $237-255$
Rode, M., and U. Suhr, 2007. Uncertainties in selected river water quality data. Hydrol. Earth Syst. Sci. 11(2): 863-874.

Ruiz, L., S. Abiven, C. Martin, P. Durand, V. Beaujouan, and J. Molénat. 2002b. Effect on nitrate concentration in stream water of agricultural practices in small catchments in Brittany: II. Temporal variations and mixing processes. Hydrol. Earth Syst. Sci. 6(3): 507-513.

Walling, D. E., B. W. Webb, and J. C. Woodward. 1992. Some sampling considerations in the design of effective strategies for monitoring sediment-associated transport. In Erosion and Sediment Transport Monitoring Programmes in River Basins, 279-288. Publ. No. 210. Wallingford, U.K.: IAHS.

Wang, X., J. R. Frankenberger, and E. J. Kladivko. 2003. Estimating nitrate-N losses from subsurface drains using variable water sampling frequencies. Trans. ASAE 46(4): 1033-1040. 